This item was submitted to Loughborough's Research Repository by the author.

Items in Figshare are protected by copyright, with all rights reserved, unless otherwise indicated.

\title{
Optical filtering of solar radiation to increase performance of concentrator systems
}

\section{PLEASE CITE THE PUBLISHED VERSION}

http://dx.doi.org/10.1109/PVSC.2002.1190918

PUBLISHER

(C) IEEE

VERSION

VoR (Version of Record)

\section{LICENCE}

CC BY-NC-ND 4.0

\section{REPOSITORY RECORD}

Sabry, M., Ralph Gottschalg, Thomas R. Betts, M.A.M. Shaltout, A.F. Hassan, M.M. El-Nicklawy, and David Infield. 2019. "Optical Filtering of Solar Radiation to Increase Performance of Concentrator Systems". figshare. https://hdl.handle.net/2134/8201. 
This item was submitted to Loughborough's Institutional Repository (https://dspace.lboro.ac.uk/) by the author and is made available under the following Creative Commons Licence conditions.

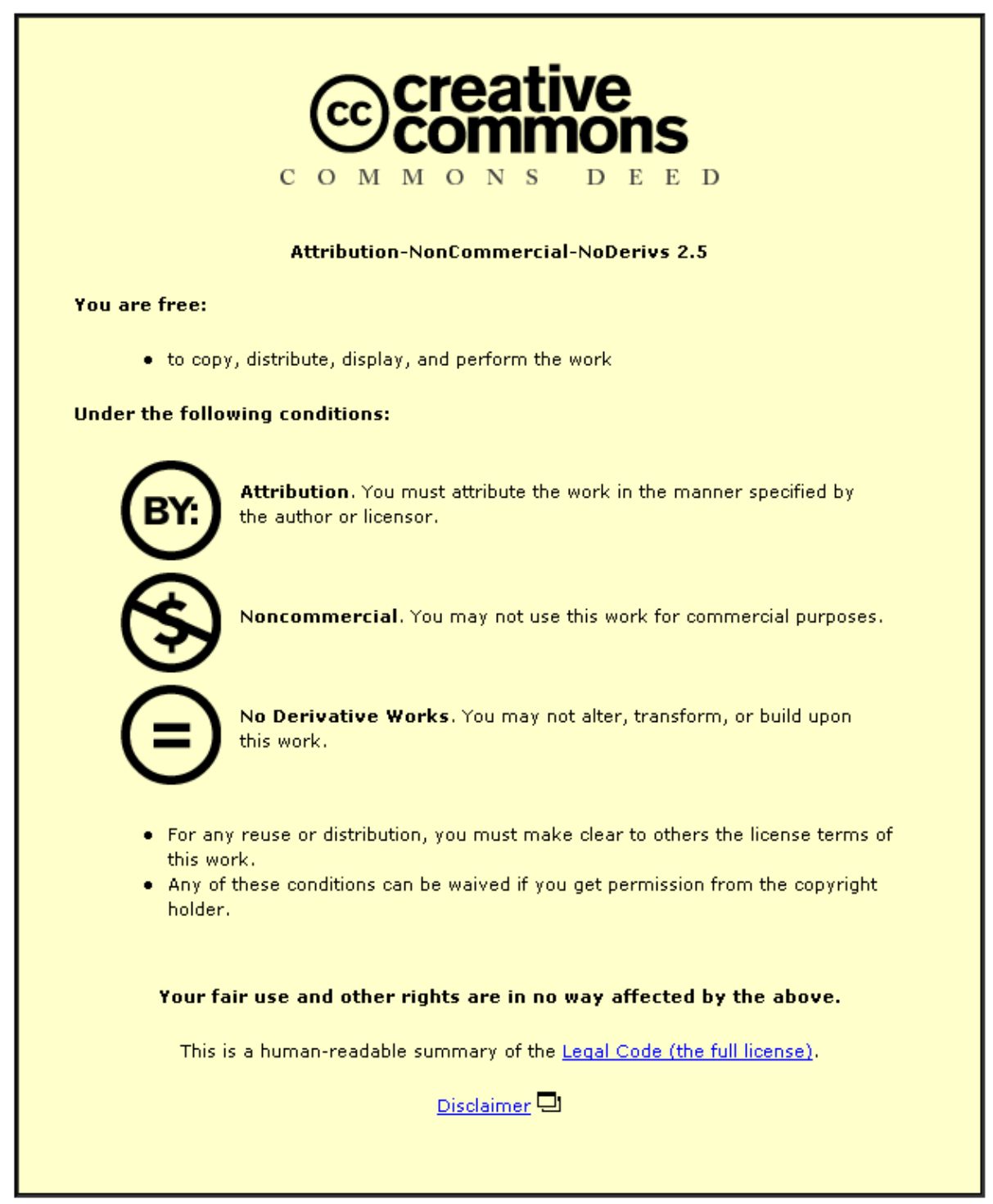

For the full text of this licence, please go to: http://creativecommons.org/licenses/by-nc-nd/2.5/ 


\title{
OPTICAL FILTERING OF SOLAR RADIATION TO INCREASE PERFORMANCE OF CONCENTRATOR SYSTEMS
}

\author{
M. Sabry' ${ }^{1,}$, R. Gottschalg', T. R. Betts', M. A. M. Shaltout ${ }^{2}$, A. F. Hassan ${ }^{3}$, M. M. El-Nicklawy ${ }^{3}$, D.G. Infieid ${ }^{1}$, \\ 1 Centre for Renewable Energy Systems Technology, Loughborough University, UK \\ 2 Solar Physics Laboratory, National Research Institute of Astronomy and Geophysics, Egypt \\ 3 Physics Department, Helwan University, Egypt
}

\begin{abstract}
Solar cell overheating due to high irradiation levels is a significant problem facing concentrator systems. Some form of cooling is needed to maintain the highest possible performance of such systems. Liquid filters may be used to inhibit unwanted solar radiation from reaching the cell and thus limit cell-operating temperatures. The performance of the cooling will depend on the optical properties of the liquid filter applied, as illustrated in this paper on the basis of different filters. An ideal filter is identified and its effects on the systems are described. It is shown, on the basis of system modeling calculations, that cell performance could be increased by up to $25 \%$ using an ideal filter. Such a system can reach an efficiency of $22 \%$ in a realistic working environment compared to a STC value of $16 \%$. The absorbed part of the incident radiation can be used as a heat source, so adding to the potential value of the system.
\end{abstract}

\section{INTRODUCTION}

The efficiency of silicon solar cells tends to increase with increasing irradiation, and of course the material is expensive. Solar concentrator systems might thus be a route to cheaper electricity and hence are attracting significant interest. Two principal advantages of concentrating sunlight in photovoltaic applications are [1]:

1- the solar cells can embody a lower fraction of the system cost, since they are the most expensive part of the PV system, and

2- higher conversion efficiency is possible, mainly stemming from the cell voltage increase logarithmically with radiation intensity.

Solar cells are prone to overheating under high irradiation levels as shown e.g. by Shaltout et al. [2]. This is crucial, as the efficiency of solar cell decreases significantly with increasing temperature, typically by about $0.5 \% / \mathrm{C}[3]$. Solar cells can utilize only a fraction of the solar radiation spectrum depending on their spectral response. The part of the spectrum that is outside the spectral response of the solar cell contributes to over-heating of the device, which results in a decrease in conversion efficiency. Better performance can be achieved by preventing this unwanted irradiation from reaching the cell, which will result in a lower operating temperature for the cell. Previous work has discussed different methods for decreasing cell temperature by means of filtering, such as dichroic beam splitters, which divide the incident solar radiation into two parts, and direct each to be incident on a different cell. with suitable spectral response [4]. This method has the advantage that it uses the energy that would otherwise be wasted. It is not clear, though, that this will reduce the overall system cost significantly as non-standard solar cells have to be used. Another approach based on rejection of the light is the use of custom made reflective coatings in the concentration system, however in this arrangement the potentially useful thermal energy is wasted.

In this paper, a combined heat and power system is proposed, that utilizes the energy outside the spectral response range of the cell, thus increasing the overall system performance. The unwanted radiant energy can be made useful if it is transformed into a medium temperature thermal flux by introducing a liquid filter, effectively adding a solar thermal collector in front of a solar cell. The advantages of introducing a liquid filter are that:

- It could work under higher levels of illumination.

- No isolation or leakage problems appear like those in back cell water-cooling systems.

- Absorbed radiation is delivered as thermal energy.

The device chosen here is a Si laser-grooved-buriedcontact technology cell, commercialized as BP-Saturn that is known to operate well in solar concentrators [5].

The proposed system, as in Fig. 1, comprises a $100 \mathrm{~cm}^{2}$ cell covered with a liquid filter, which is contained in a thin chamber with optical glass front and rear surfaces. Solar radiation is incident on the front surface of the liquid filter; only the transmitted radiation is incident on the solar cell's surface

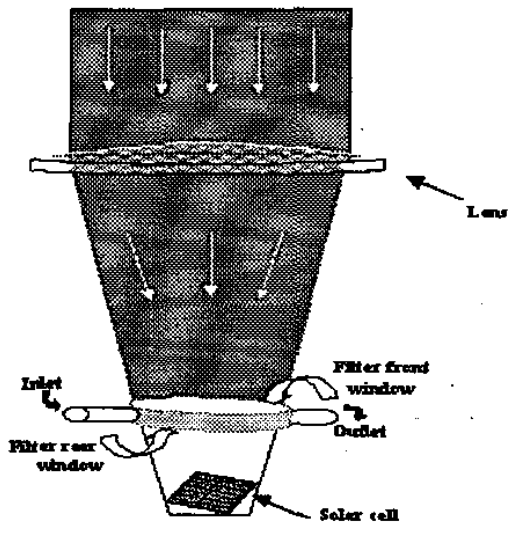

Fig. 1. Schematic diagram of the proposed system 
The liquid enters, and leaves the filter chamber with temperatures $T_{i}$ and $T_{0}$ respectively. In order to understand the influence of filtering on the performance of the solar cell, an optimum filter configuration is identified, and the influence of this ideal filter is investigated here. This configuration can be applied later with commercially available liquids, in order to actual anticipated system performance.

\section{SYSTEM MODELING}

A simulation program for modeling the proposed system behavior and performance was developed using Delphi. The system model is divided into two main parts. The first deals with thermal modeling of the solar cell as a result of operation under variable radiation and ambient temperature values. The second part deals with calculations of the electrical parameters of the cell, such as short circuit current $\left(t_{\mathrm{sc}}\right)$, open circuit voltage $\left(V_{\mathrm{oc}}\right)$, maximum power (M.P), and Efficiency ( $\eta$ ) corresponding to the calculated operating cell temperature and incident irradiance.

\section{Thermal Modeling}

The cell operating temperature is calculated using a thermal model presented by Fuentes [6], which solves the energy balance equation of a photovoltaic device in real operating conditions. The model considers convective heat losses and radiative heat exchange to the sky and ground. The parameters assumed for this model are: wind speed $=1 \mathrm{~m} / \mathrm{s}$, cell emissivity and absorptivity $=0.84$ and 0.83 respectively, cell thermal capacity $=1100 \mathrm{~J} / \mathrm{m}^{2} .{ }^{\circ} \mathrm{C}$, INOCT $=49^{\circ} \mathrm{C}$, and clearness index $=0.9$.

\section{Electrical Modeling}

In order to find the electrical output of the solar cell incorporating certain spectral radiation conditions, the program assumes an incident AM1.5 spectrum. Based on the known spectral transmission of the filter, both total and spectral irradiance of the transmitted radiation are calculated. The corresponding $J_{s c}$, is given as:

$$
J_{s c}=\int S R(\lambda) \cdot G(\lambda) \cdot T(\lambda) \cdot \lambda d \lambda
$$

where $\lambda$ is the wavelength, $S R(\lambda)$ is the spectral response of the cell, $T(\lambda)$ is the spectral transmission of the filter used, and $G(\lambda)$ is the irradiance measured in $W^{-2} \mathrm{~nm}^{-1}$. The simulation program generates a complete $\mathrm{I}-\mathrm{V}$ curve using the two-diode model based on the cell's data sheet parameters: Subsequently, the device performance parameters could be evaluated.

\section{Model Validation}

Cell efficiency is calculated as the ratio of the maximurn power delivered by the solar cell, to the solar irradiance transmitted through the filter and incident on its surface. Generally, modeled cell parameters show strong correlation with the measured parameters, indicating that these calculated parameters are suitable for use in further calculations. Measured and calculated efficiencies at a cell temperature of $27^{\circ} \mathrm{C}$ are shown in Fig. 2. Modeled effi- ciency is slightly higher than that of measured, because losses such as cell reflectivity and external leads resistance are not included in the simulation process. The reduction in the calculated efficiency of the cell at unregulated temperature at different intensities is also shown in order to emphasize the importance of cooling.

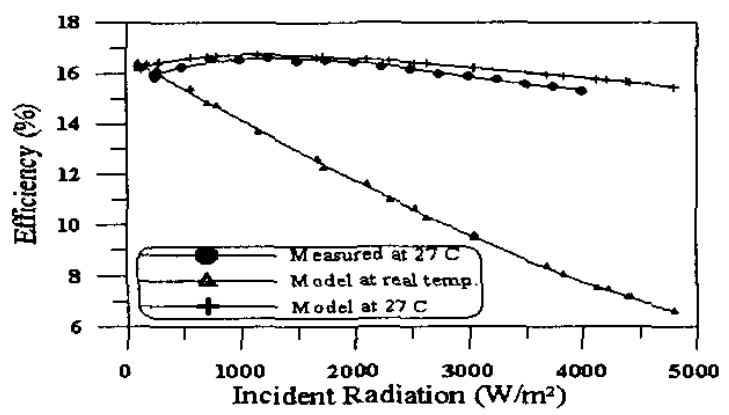

Fig. 2. Measured and modeled efficiencies as a function of radiation intensity at cell temperature $27^{\circ} \mathrm{C}$, and modeled efficiency at calculated cell temperature.

\section{IDEAL FILTER ESTIMATION}

In order to investigate theoretical performance of the solar cell coupled with such a filter, the spectral transmission of optimum filter should be defined. Firstly, the maximum power of the solar cell is calculated using the model under a given amount of incident radiation without any filter. Then, a filter is introduced which is assumed to have spectral transmission as in the following equation:

$$
\text { ST. }= \begin{cases}0 & \lambda>x 1, \lambda>x 2 \\ 0.95 & x 1<\lambda<x 2\end{cases}
$$

where $x 1$ and $x 2$ are the left and right edges of that filter. These left and right edges are evaluated, and the influence on the device output is investigated. It should be emphasized here that, thermal effect of the incident radiation is also considered when evaluating the filter, i.e. not only magnitude of the irradiation is of importance but also its heating impact. The right edge of the liquid filter is initially assumed to be $1100 \mathrm{~nm}$, coinciding with the upper boundary of the response band, and is moved downwards in $10 \mathrm{~nm}$ steps, and in each step the program calculates the maximum power of the cell, which is observed to increase with moving the right edge of the filter in this manner, until an optimum point is reached, which corresponds to the highest performance of the cell. Having fixed the right edge at that optimum value, the same procedure is repeated in order to find the left edge, now stepping the wavelength up from an initial value of $300 \mathrm{~nm}$. The optimum filter is found to have a transmission in the region $450-920 \mathrm{~nm}$, as shown in Fig. 3 with a total transmission of $59 \%$. The solar cell quantum efficiency is plotted in the same figure to show the included and rejected parts.

\section{PERFORMANCE ENHANCEMENT}

System modeling is carried out on a daily basis, as this is a more realistic way of assessing system performance. 


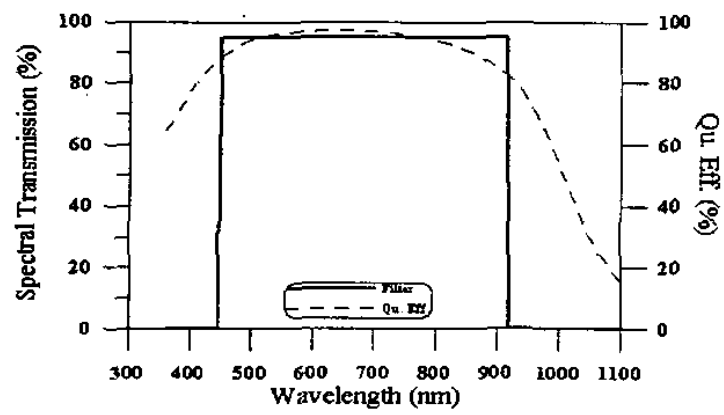

Fig. 3. Spectral transmission of the optimum filter, along with the quantum efficiency of the cell used.

An irradiance and daily ambient temperature profile from measured data, as shown in Fig. 4, is applied to a solar concentrator, variable concentration ratios are assumed.

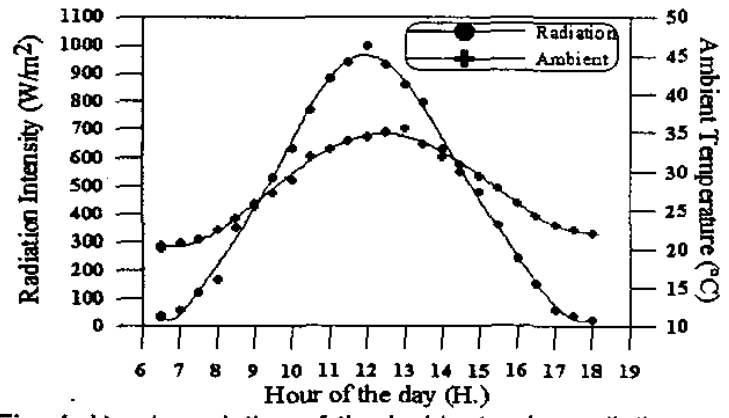

Fig. 4. Hourly variation of the incident solar radiation and ambient temperature.

Performance of the solar cell is calculated and compared for three solar intensity regimes:

- 1 Sun, i.e. unconcentrated solar radiation without using any filter, as the baseline

- 7 Suns, without using filter, as it is the highest intensity that can be incident on the cell without reducing its electrical output significantly.

- 11 Suns, using the ideal filter derived above, because the transmitted intensity is nearly identical to that of the second regime.

Modeling show that cell temperature could reach more than $160^{\circ} \mathrm{C}$ at 7 Suns around noontime without the use of filters. The simulation confirms that cell temperature is remarkably decreased when using the ideal liquid filter. For comparison, Fig. 5 shows cell temperatures at 1 and 7 Suns without using filter and, 7 and 11 Suns using filter. Elevated cell temperature will have a direct impact on the $V_{o c}$, which displays a reduction around midday, although an increase in irradiance normally would cause an increase in $V_{o c}$. As shown in Fig.6, this reduction in the $V_{o c}$ is not an artifact of using the filter, as it is also experienced by a 1 Sun system operating without any filter. $V_{o c}$ of the 11 Suns filtered regime is higher than that of the 7 Suns unfiltered regime. This is because the cell temperature is slightly lower and because of the improved matching of the incident spectral irradiance to the cell response.

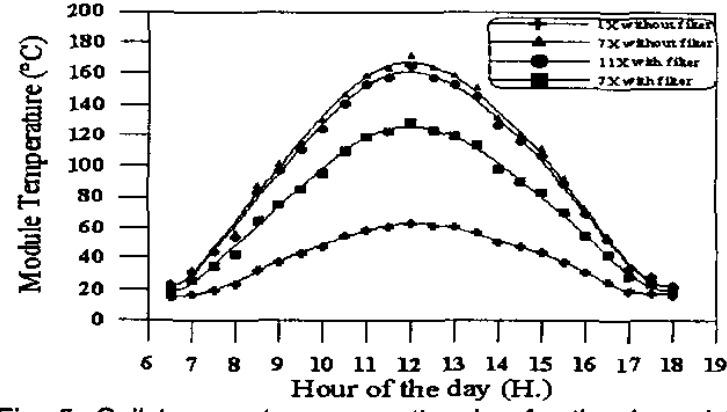

Fig. 5. Cell temperatures over the day for the 1- and 7 Suns without using filter and, 7 and 11 Suns using filter.

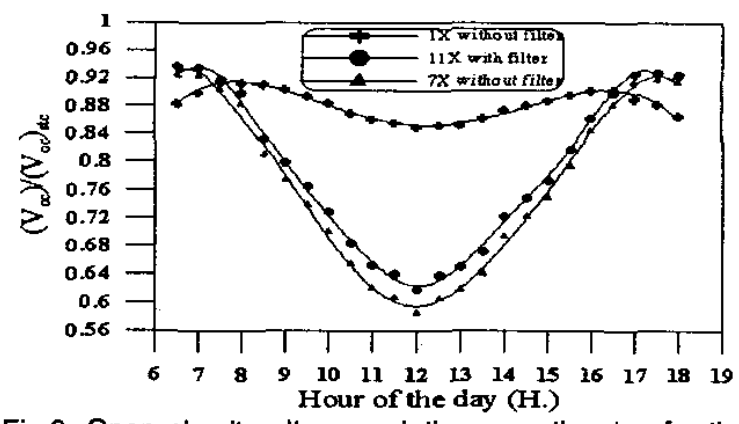

Fig.6. Open circuit voltage variation over the day for the three regimes.

$\mathrm{I}_{\mathrm{sc}}$ is linearly related with cell temperature. Thus one would expect the maximum $I_{s c}$ to be at noon time, as in Fig. 7.

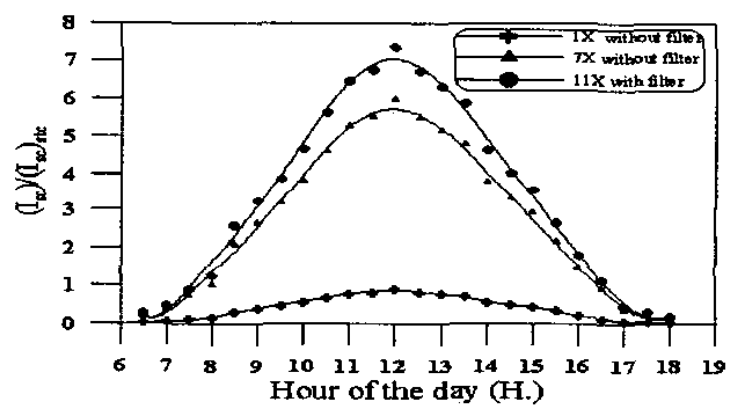

Fig. 7. Hourly variation of short circuit current for the three regimes.

Despite the irradiance for the filtered and the unfiltered regimes being chosen to be equal, the filtered system produces higher current; an increase of $22 \%$ is observed. Again, this is due to the improved matching of incident irradiance and spectral response of the cell. The enhancements of the filtered system in both current and voltage translate into an improved power generation, as shown in Fig. 8. The power of the filtered system shows a gain of $24 \%$ at noontime over the unfiltered system. The drop in the power at midday is a thermal effect, due to the increased cell temperature. 


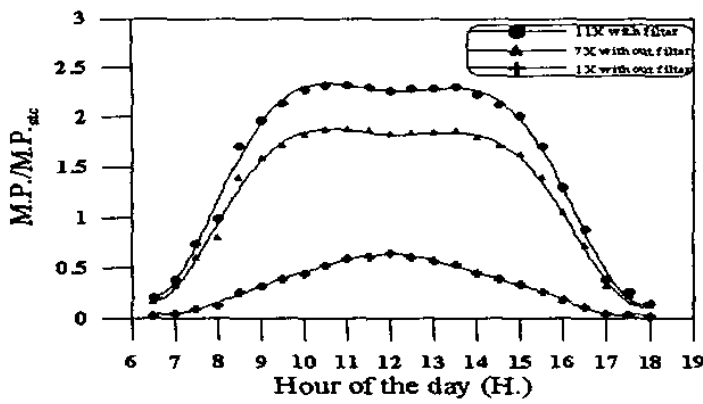

Fig. 8. Hourly variation of the maximum power of the solar cell for the three different illumination regimes.

Efficiency behavior is shown in Fig. 9. The figure shows a drop at midday for all illumination regimes.

The unfiltered 1 Suns regime, has a value around $14 \%$ at noon, and is reduced dramatically by increasing the illumination intensity to 7 Suns to around $5.6 \%$ as an effect of increasing both radiation and temperature.

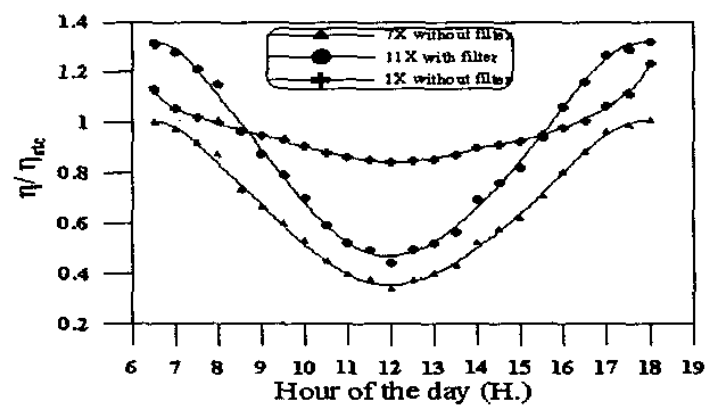

Fig. 9. Hourly variation of the efficiency for the different ilfumination regimes

Enhancement of the efficiency using the optimum filter at 11 Suns is demonstrated in the same figure, as spectrum quality becomes closely matched with the cell spectral response.

The efficiency of the solar cell running in the filtered regime has a value of about $7.3 \%$ at noon, i.e. it is increased by about $30 \%$ compared to the unfiltered 7 Suns mode, although radiation intensities of both regimes are nearly the same.

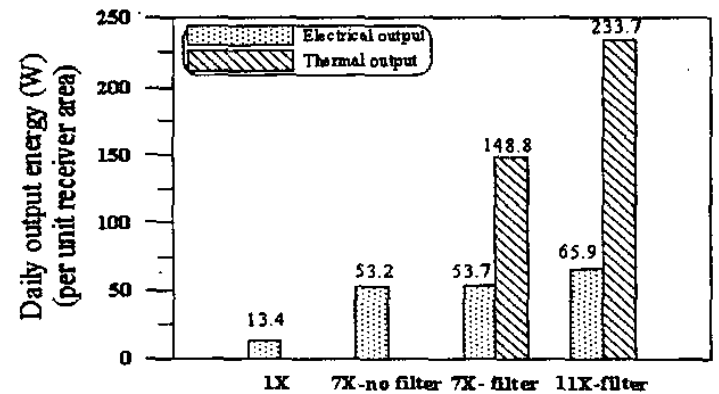

Fig. 10. Daily output energy/receiver area of the different regimes
Finally, the total energy gain of the system is illustrated in Fig. 10. The daily-accumulated energy of the different regimes is compared. The graph compares four regimes, which are: 1 Suns unfiltered, 7 Suns unfiltered, 7 Suns filtered, and 11 Suns filtered regimes. Although the 7 Suns filtered regime receives less radiation for electric conversion than that of 7 Suns unfiltered regime (as the filter removes about $40 \%$ of the solar radiation by absorption), the former also produces useable heat. The 11 Suns filtered system delivers about $65.9 \mathrm{~W}$ and $233.7 \mathrm{~W}$ as electrical and thermal output respectively.

\section{CONCLUSIONS}

A PV concentrator system using a liquid filter has been demonstrated to significantly reduce cell-operating temperature. The irradiance filtered out can be used to provide useful thermal gain, thus significantly increasing the overall system efficiency.

An ideal filter has been identified, having maximum spectral transmission in the region $450-920 \mathrm{~nm}$. Enhancement of the solar cell's electrical output was calculated based on the application of such a filter, and the efficiency was found to be increased by about $30 \%$, due to cell cooling and improved spectral matching. Thermal gains due to radiation absorbed in the filter were also calculated as being equivalent to about $40 \%$ of the concentrated radiation incident on the system.

\section{Acknowledgements}

The authors want to thank K.Heasman and S.Ransome, BP Solar, for supplying the cell specific data and the helpful discussions.

\section{REFERENCES}

[1] Daniel Feuermann; Jeffrey M.Gordon; High concentration photovoltaic designs based on miniature parabolic dishes, Solar Energy 2001; 70: 423-430.

[2] M.A.M.Shaltout; A.E.Ghettas; M.Sabry; V-trough concentrator on photovoltaic full tracking system at hot desert climate, Renewable Energy 1995; 6: 527-532.

[3] R.Gottschalg; Introduction to PV Cell Technology; in A.Sadrul Islam; D. Infield (Ed.): Photovoltaic Technology for Bangladesh. BUET, Dhaka, 2001, pp. 23-40.

[4] L.Desandre; D.Y.Song; H.A.Macieod; M.R. Jacobson; D.E. Osborn; Thin film multilayer filter designs for hybrid solar energy conversion systems; Proc. SPIE. 1985.

[5] BP saturn cell specific data, supplied by BP Solar.

[6] M.K.Fuentes; A Simplified Thermal Model for Flat Plate Photovoltaic Array. Sandia Report No. SAND85-0330, Sandia National Laboratories, Albuquerque, 1987. 